\title{
Business Management Wisdom in "Diamond Sutra"
}

\author{
Xin Zhao ${ }^{1, a}$, Haowei $\mathrm{Ti}^{2, \mathrm{~b}}$,Ding $\mathrm{Ma}^{3, \mathrm{c}}$ \\ ${ }^{1}$ Limkokwing University of Creative Technology PGC Kuala Lumpur, Malaysia \\ ${ }^{2}$ Limkokwing University of Creative Technology PGC Kuala Lumpur, Malaysia \\ ${ }^{3}$ Limkokwing University of Creative Technology PGC Kuala Lumpur, Malaysia
}

\begin{abstract}
It has been more than ten years since I started to study business management. There is no doubt that the modern management discipline originated with the West, and the West is the birthplace of modern management theories and methods. This kind of management theory and method, which originated from the industrial revolution in the West, took enterprises as the basic management unit, and relied on the two mechanisms of market economy and technological revolution. Western management concepts have been widely disseminated and applied around the world, deeply affecting the management practices of companies around the world.

The strategic positioning of an enterprise is determined by the trend of the external environment and the destiny of the enterprise. The destiny of an enterprise is a management element that cannot be ignored, just like what Buddhism said: "Bodhisattva will also lose cause and effect."
\end{abstract}

\section{Introduction}

The "Diamond Sutra" is so profound that it cannot be said. To manage an enterprise to achieve happiness in life, it is undoubtedly to start from the heart. Modern business management is human management. If our hearts are full of greed and jealousy, then the world must be full of crimes such as stealing, robbery, deceit, and rape. People have a healthy state of mind, which is the foundation of happiness. The logical structure of the "Diamond Sutra" applied in modern language is as follows: "Manager, that is, non-management, names management". Such logical structures abound in the "Diamond Sutra", as the following excerpt:" Buddha tells Su Bodhisattva. All aspects. They are all vain. If you see all aspects, you see Tathagata."'Subhuti. The so-called Dharma person. That is not the Dharma." "The solemn Buddha soil. That is not the solemnity. The name is solemn." "The Buddha says Prajna Paramita. It is not Prajna Paramita. It is the name Prajna Paramita." ${ }^{[1]}$ The "Diamond Sutra" also tells us that business management should be based on the selflessness, which also illustrates the difference between ordinary people and bodhisattvas in terms of the difference between self and no self. Mortal people have me everywhere, for my sake, even if they are altruistic, they will not lose themselves. Employees are always utilitarian, because when they are altruistic, they first consider their own interests, so that they cannot serve the company unselfishly. How can we better manage the enterprise? Therefore, the "Diamond Sutra" gives us management wisdom. The sutra says: If a bodhisattva has self-image, human-image, sentient beings, and longevity, it is not a bodhisattva. The "Diamond Sutra" says that "all appearances are all vain. If you see all appearances, you will see the Tathagata."

\section{Management in the Diamond Sutra}

\subsection{Management in Diamond Sutra}

Buddhas and Bodhisattvas are "selfless". As the vast majority of managers, it is difficult to achieve "selflessness". Not only can it not be done, but like thousands of contemporary people, the emphasis is on self-realization. The psychologist Maslow even regards self-realization as the most important of the five basic needs of people. So, should managers emphasize self and despise "non-self"? Absolutely not. Based on the analysis of many management cases, we will find a dialectical phenomenon: the more we can let go of ourselves, we can achieve a better self.

There is no doubt that today's business world is a place where talents gather. Merchants possess power and abilities that ordinary people cannot match. They try their best to achieve a certain goal. They provide the public with products and services worth billions of dollars, continuously improving quality, shortening construction periods, and reducing costs. The core of their lives is innovation and efficiency-they are a unique group in society. The businessman is meticulous, thorough, tough and insightful. ${ }^{[2]}$ People without these qualities cannot survive in the mall. There is a pure land in doing business, with its unique "natural selection" process: if you are not successful, then no matter how high or low your position in the company is, it will not last long. If you cannot participate in the output, your boss, manager, and even 
your colleagues will remove you from them. We often see this situation: it's like the blood in the human body rejects foreign antibodies. The best businessmen have a deep inner strength-they are like us, and even more eager for a true spiritual life than us. They are more knowledgeable than most of us; they know what the world can give them and what the world cannot give them. They emphasize logic in their spiritual life: methods and results must be clear, just like commercial treaties. They often interrupt a certain kind of practice-not because they are greedy or lazy, but because they have not found any path that meets their requirements. The Diamond Sutra was created for those who are smart, strong, and clever. Don't think that as a businessman, they don't have the opportunity, time, and personal qualities to live a true spiritual life, and don't think that doing business is incompatible with maintaining a deep spiritual life. Don't think that as a businessman, they don't have the opportunity, time, and personal qualities to live a true spiritual life, and don't think that doing business is incompatible with maintaining a deep spiritual life.

If this logic is true, it is extremely terrible, which means that all management theories are untenable, and all management methods are obsessive and need to be broken. ${ }^{[3]}$

Because "point to the moon with the finger, and not to refer to the moon", there is no word in the Prajna wisdom, and the finger is never the moon. But we must not be obsessed with the absence of literal phase, because nonphase is also phase. It is like drilling wood to make fire. The drill and the driller rub against each other. When the fire (prajna wisdom) arises, the drill and the driller will be eliminated at the same time.

\subsection{Maintaining the Integrity of the Specifications}

The following article provides a structure to break other management thoughts, and in the process of breaking. The structure provided in this article will also be broken, and only in this way can real management wisdom arise. ${ }^{[3]}$

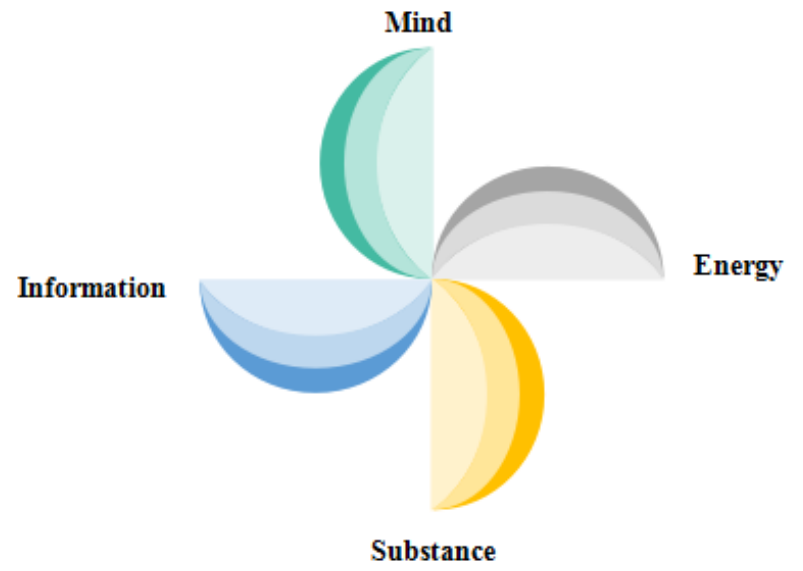

Fig 1. Objects of enterprise management

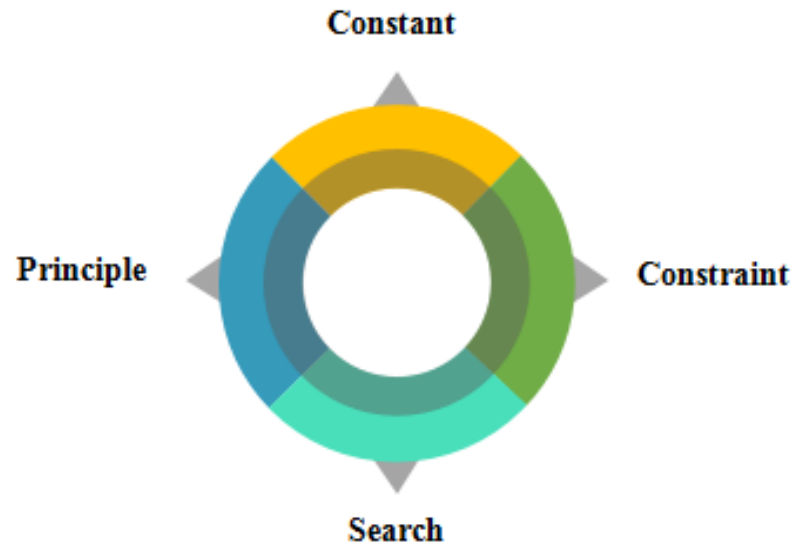

Fig 2. The meaning of business management

As shown in Figure 1 and Figure 2:

It looks at the enterprise from the four dimensions of "mind, energy, information and substance"; it also regards the enterprise as a system composed of "mind, energy, information and substance". "Economy, business, management, and financial management" correspond to different dimensions or elements. See the table below:

\begin{tabular}{|c|c|c|}
\multicolumn{2}{c}{ Table1. } & Management structure \\
\hline Measure & Object & $\begin{array}{c}\text { The meaning of } \\
\text { management }\end{array}$ \\
\hline Economy & Mind & Constant \\
\hline Business & Substance & Search \\
\hline Management & Energy & Constraint \\
\hline Financial management & Information & Principle \\
\hline
\end{tabular}

The characteristic of this analysis structure is that it is not obsessed with the dispute over whether management is science or art, nor is it obsessed with the traditional definition of the purpose of the enterprise to create profits. Instead, it assumes the enterprise as an organic life body. Assuming that an enterprise is a natural extension and amplification of a person, all functions of an enterprise are the manifestations of human life functions and human nature.

\section{Strategic management implied in the Diamond Sutra}

B"Soldiers, deceitful means", "soldiers are not tired of deceit", "soldiers stand by deceit", these points of view all show that the strategic point of military warfare is not to be honest and to make full use of fraud. Commercial warfare is on the contrary. Commercial warfare requires honesty and credibility, and fraud cannot be used. From this, we can see that the core of business strategy is "credit." The essence of business strategy management is the establishment and construction of corporate credit. ${ }^{[4]}$

In the article "The Essence of Corporate Culture Is the Emergence of Belief", the chart provided expresses such thoughts (see Figure 3 below): 


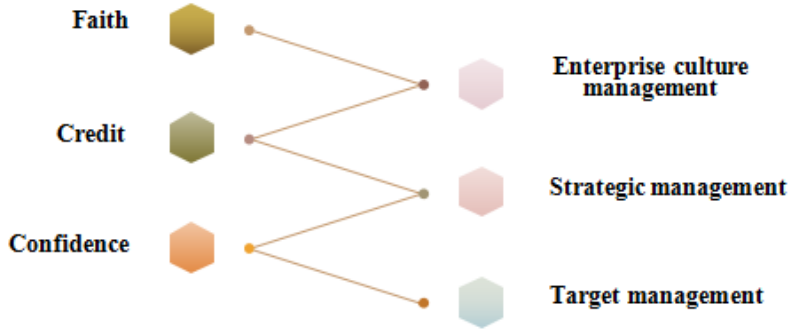

Fig 3. The essence of enterprise culture is the emergence of faith

\subsection{Enterprise culture}

To illustrate the problem, we divide time into three phases: "past, present, and future". See the Table 2 below:

Table2. Time dimension positioning

\begin{tabular}{|c|c|c|}
\hline Time & $\begin{array}{c}\text { Management } \\
\text { content }\end{array}$ & Enterprise (Mind) Management \\
\hline Passed & Vision & Enterprise culture \\
\hline Now & Mission & Enterprise strategy \\
\hline Future & Purpose & Enterprise goals \\
\hline
\end{tabular}

Enterprise culture is the inheritance of history, more precisely, the inheritance of the history of the members of the organization. It includes not only the history after the establishment of the enterprise, but also the history before the establishment of the enterprise.

People's subconsciousness is difficult to recognize, but the subconsciousness will be projected onto certain types of symbols. This is the principle of religion. The so-called totems, gods, gods, and Buddhas are actually the projection of the human subconscious mind and a tool for humans to use the subconscious mind.

Positioning is not only a concept of space, but also a concept of time. It needs to maintain this positioning throughout the entire life cycle of the enterprise, until the enterprise becomes the number one in this positioning, establishes an irreplaceable competitive advantage, and becomes an integral part of the social system.

In fact, companies are in an uncertain and changing environment, their strategic positioning will often be impacted, and they are often faced with the test of whether to change. How to maintain this positioning in the time dimension?

\subsection{Strategic management}

Based on this assumption, the conclusions that can be drawn are: All the activities of the enterprise adapt itself to the external environment, live in harmony with the outside world, and coexist with the environment. All the activities of the enterprise are for their own survival and reproduction. The following article is looking for a management theory to "make fire with wood". [6]

Strategic management is actually a rhetorical expression of management. Taking the "War of Chibi" as an example, the strategy determined by $\mathrm{Zhou} \mathrm{Yu}$ and Zhuge Liang is a fire attack, and they have carried out a series of matching names for the implementation of the strategy. It is a term used by Michael Porter, which refers to a series of things done for the strategy, and also refers to the resources allocated for the strategy, such as: serial schemes, countermeasures, and bitter tricks. In addition, the fire attack has an important strategic element-east wind.

It was this "East Wind" that almost killed Zhou Yu. Fortunately, Zhuge Liang was there. Otherwise, the entire Soochow Society would be burned and the success would be defeated. A person like Zhuge Liang has only come out for thousands of years. Can strategy be managed? We generalize the term management, and there is only one result, and that is the death of management. There is only one possibility of medicine that can cure all diseases, and that is fake medicine. ${ }^{[5]}$

Opponents will say: The example cited in this article is an extreme case and not universal. There is no such extreme in business activities. There is no need for the wisdom of Zhuge Liang. It can be managed through strategic management tools, such as SWOT, Boston Five Forces Model, competitive strategy (differentiation, cost leadership), game theory, etc. This is indeed the case. Commercial activities (commercial warfare) and war (warfare) are indeed fundamentally different. The former is a gambling with wealth, while the latter is a gambling with life. Therefore, strategy is applied to business management only for the convenience of writing. It is a management rhetoric, and the word "strategy" is used to express its importance. This "strategy" is not another strategy, and the "strategy" is used.

\section{Conclusion}

The purpose of an enterprise is to consider from the inside of the enterprise organization. It is the internalization of the mission. It refers to the method and path the enterprise will use to achieve a specific goal. The description of this goal is usually qualitative to determine the direction of the organization's development and future state. Of course, the purpose of the company will be broken down into specific goals in different development periods. The expression of corporate vision, strategic positioning (description of corporate mission) and corporate purpose is often not easy to spread due to too much text, nor is it suitable for everyone. Unify the thinking of members internally and publicize their own positioning externally to facilitate customers' cognition and interaction with the company. It is also a one-sentence expression of the corporate vision, thus awakening the inexhaustible power in the mind. ${ }^{[7]}$

In modern society, with the acceleration of the pace of life and the increase in pressure from work and study, the relationship between people deteriorates, and more and more people begin to suffer from mental illness. Such as horror, anxiety, depression, helplessness, even schizophrenia, personality mutation, etc. But the psychological counseling work in our country has just started, and it is far from meeting people's needs. Therefore, these dilemmas must be resolved on their own. In this case, people may be able to get some useful enlightenment from the Diamond Sutra. The wisdom of life in the "Diamond Sutra" provides a feasible way for modern people to relieve their worries, increase happiness, and enhance the meaning of life. It has an effect unmatched by general management. 


\section{Acknowledgment}

When this paper was completed, I felt a lot of emotion!

First of all, I want to thank my respected tutor, Siti Aida Samikon, for her meticulous guidance on my thesis, the selection of the thesis theme, the construction of the article frame, the supply of relevant materials, the revision of the later stage and other valuable suggestions made, so that I successfully completed this article; I am grateful to her for her meticulous care in all aspects of my study, work, and life in the past three years. She not only granted me knowledge without reservation, but also taught me the principles of being a person and doing things. The scientific and rigorous academic spirit, the conscientious work attitude, and the broad, keen and innovative design thinking all influence me subtly, and I have benefited a lot from precepts and deeds.

I am grateful to Limkokwing University of Creative Technology for creating good learning conditions and a strong academic atmosphere, allowing us to spend three years of pleasant and unforgettable learning time; I am grateful to all the teachers, the professional knowledge you impart will become my precious wealth, Used for life.

I am grateful to my dear family and friends, the three years of study and life have both pains and joys!

Heartfelt thanks!.

\section{References}

1. Shan aoyang, He Qiang. On the thought of "the heart without being born in the Diamond Sutra" and its contemporary humanistic implication[J]. Journal of Cultural Studies, 2020(05): 70-73.

2. Wu Yukun. Dialectical thinking in the Diamond Sutra[J]. Journal of Puyang Vocational and Technical College, 2019, 32(05): 15-18.

3. Huo Sitong. Comparison of the Differences of Negation in the Classics of Confucianism, Taoism and Buddhism and Its Cultural Implications [C]. Proceedings of the 2014 International Symposium on "Language Description and Interpretation".: Department of Chinese Language and Literature, Fudan University, 2014: 58-67.

4. Wang Sujun. On the relationship between the moral values in the Diamond Sutra and its religious principles [J]. Wutai Mountain Research, 2012(03): 14-17.

5. Li Yun. Research on the Philosophical Thoughts of "Diamond Sutra" [D]. Shaanxi Normal University, 2011.

6. Wang Xu. Buddhist thought of self-cultivation and its practical significance[D]. Xidian University, 2010.

7. Xiong Bingyuan. Economic interpretation of "Diamond Sutra"[J]. Journal of Southwest University for Nationalities (Humanities and Social Sciences Edition), 2006(06): 52-60 